\title{
'|||||||||||||||||||||||||||||||||||||||||||||||||||||||||||||||||||||.
}

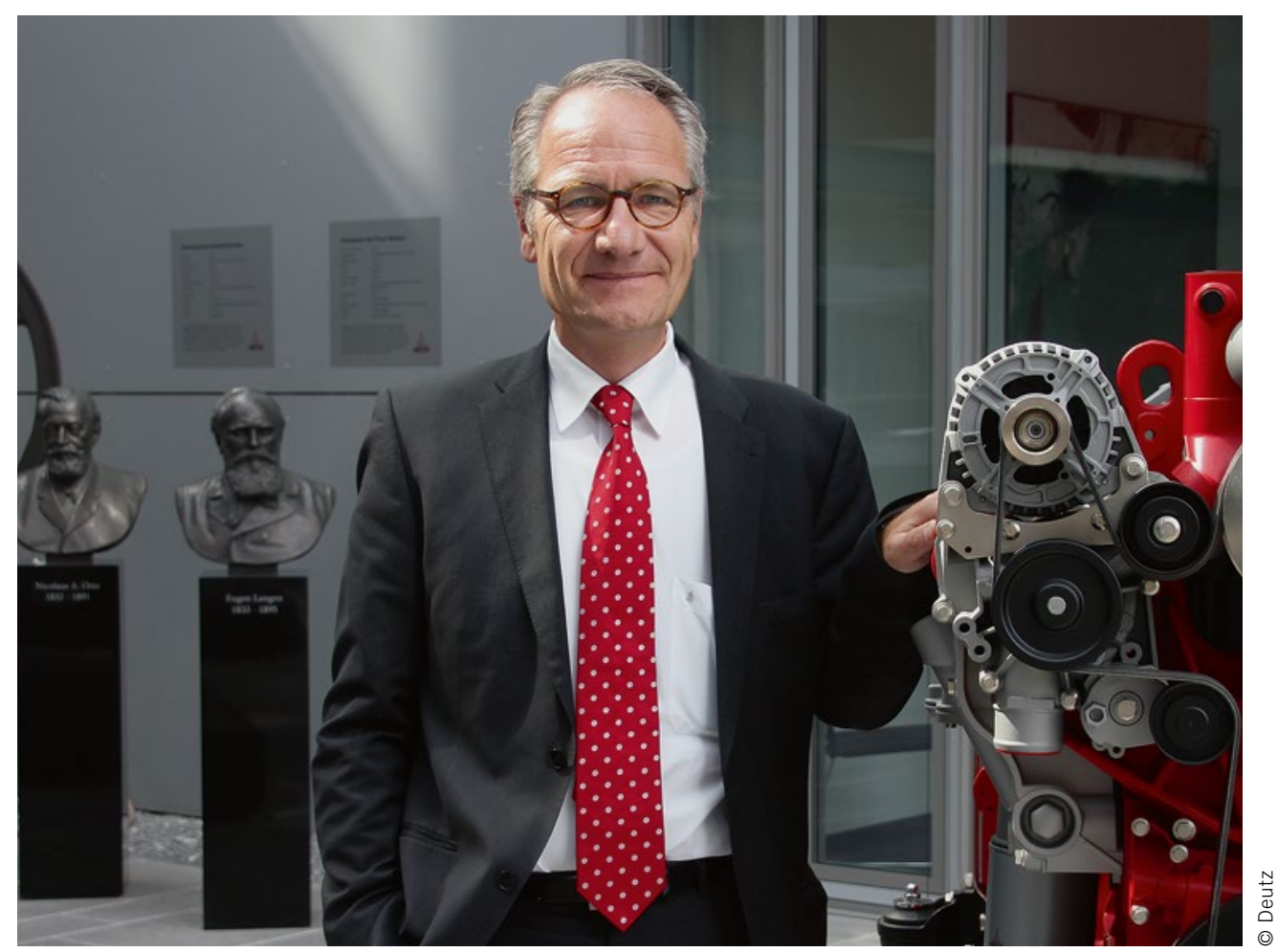

Dr.-Ing. Markus Schwaderlapp Senior Vice President Research \& Development, Deutz AG

\section{Fit für die Zukunft}

Mobile Arbeitsmaschinen sind eine Domäne des Verbrennungsmotors. Hier spielt dieser seine Stärken aus: Robustheit, Kompaktheit, geringer Verbrauch, große Reichweite und nicht zuletzt ein günstiges Preis-Leistungs-Verhältnis. Dies gilt für kleine Motoren in Hilfsaggregaten für Ölfördereinrichtungen jenseits des Polarkreises ebenso, wie für Hochleistungsdieselmotoren in großen Traktoren in landwirtschaftlichen Großbetrieben. Eine besondere Herausforderung für die Antriebsentwicklung im Off-Highway-Bereich stellt die Emissionsgesetzgebung dar, die weltweit in den letzten Jahren deutlich verschärft wurde. Die Stufe V, die 2019 in Europa in Kraft treten soll, stellt dabei die schärfste Anforderung - der Grenzwert für die Partikelanzahl erfordert einen geschlossenen Partikelfilter. Diese Emissionsstufe erfüllen heute bereits alle Deutz-Motoren von 2,9 bis 7,8 1 Hubraum mit Dieselpartikelfilter und sind damit eine nachhaltige Antriebslösung für die gesamte Palette der mobilen Arbeitsmaschinen. Die Steuergeräte-Software stellt dabei die Funktion der Abgasnachbehandlung im kompletten Kennfeld des Motors sicher. Zusätzlich wurden Package-Lösungen entwickelt, die die Abgasnachbehandlung in die verschiedenen Fahrzeuge vom Radlader bis zum Traktor integrieren.

Der Verbrennungsmotor hat damit seine „Hausaufgaben“ für die nächsten 10 bis 15 Jahre gemacht. Dennoch kann auch die
Elektrifizierung Vorteile in der mobilen Arbeitsmaschine bringen: milde Hybride mit 48-V-Technologie und $15 \mathrm{~kW}$ elektrischer Leistung können beispielsweise Start-/Stopp-Systeme erleichtern oder hydraulische Aggregate in der Arbeitsmaschine durch elektrische ersetzen. Eine weitere Stufe der Elektrifizierung hängt wie bei der On-Highway-Anwendung stark von der Preisentwicklung und Leistungsfähigkeit der Batterie ab. Besondere Anforderungen des Off-Highway-Einsatzes sind sicherlich die erhöhte Robustheit des Aggregats und die erforderliche Reichweite.

Ein spannendes Thema für die mobile Arbeitsmaschine ist die Vernetzung (Industrie 4.0), die intensiv bei Land- und Baumaschinen entwickelt wird. Der Motor mit Abgasanlage verfügt über ein mächtiges Softwarepaket, in dem eine Vielzahl wichtiger Daten für die Maschine erzeugt werden. Natürlich ist das Motorsteuergerät mit dem Fahrzeugsteuergerät vernetzt, sodass sich über Telemetrie der Einsatz ganzer Fahrzeugflotten optimieren lässt. Umgekehrt kann ein direkter Zugriff auf die Datensoftware im Motorsteuergerät völlig neue Möglichkeiten für den Anwender eröffnen.

Der Verbrennungsmotor wird in der mobilen Arbeitsmaschine über die nächsten Jahrzehnte dominant bleiben - Elektrifizierung und Vernetzung werden die Funktionsumfänge deutlich erhöhen. 